\title{
In Appreciation of an Outstanding Surgeon-in-Chief
}

\author{
Charles N. Cornell, MD
}

Received: 8 November 2013/Accepted: 14 November 2013 /Published online: 18 December 2013

(C) Hospital for Special Surgery 2013

Welcome to the tenth volume of HSS Journal ${ }^{\circledR}$. In reflection, 2013 was a notable year for the HSS community. Not only did we celebrate the 150th anniversary of the founding of the hospital but also the 100th anniversary of the founding of our alumni association. Thomas Sculco, MD, our current surgeonin-chief, announced that after 10 years of service, he will be stepping down. A search for his replacement is currently underway.

At the 2013 Alumni Association meeting, in his presidential address, Daniel Rich, MD chronicled many of Dr. Sculco's contributions as surgeon-in-chief. Among these was his leadership in establishing the International Society of Orthopedic Centers also known as ISOC. It was Dr. Sculco's vision to create a society of the best orthopedic centers from throughout the world to collaborate on issues of innovation in clinical care, research, and education. Currently, 17 leading orthopedic academic centers participate with meetings taking place every 18 months. Within the mission of ISOC is the charge to collaborate and build consensus around complex issues in clinical care. We are excited that ISOC has chosen the HSS Journal ${ }^{\mathbb{R}}$ as a forum for the publication of two of these consensus-building initiatives.

Benjamin Ricciardi, MD and his coauthors report on two studies, which establish a consensus for practice, which is aimed at the prevention and treatment of prosthetic joint infection. The most commonly employed methods for the prevention of surgical site infection are reviewed, and the approaches to clinical management of the infected arthroplasty are described. Although these topics have been described in other studies, these reports provide the consensus of the most active orthopedic centers in Europe and North and South America.

ISOC is an impressive accomplishment, and success is largely due to the leadership and vision of Dr. Sculco. One of his other great contributions is the HSS Journal ${ }^{\circledR}$. Without his support, the journal would not have become a reality. I am sure, and I join with every member of the HSS community and readers around the world in extending our congratulations and appreciation to Dr. Sculco for his 10 years of extraordinary service. Join me in extending best wishes for his future endeavors.

\section{Disclosure}

Conflict of Interest: Charles N. Cornell, MD receives royalty payments from Exactech Corporation, outside the work.

Human/Animal Rights: This article does not contain any studies with human or animal subjects performed by the any of the authors.

Informed Consent: N/A.

Required Author Forms Disclosure forms provided by the authors are available with the online version of this article. 